Gut, 1980, 21, 760-765

\title{
Evidence for the secretion of gastrin into human gastric juice
}

\author{
K J HENGELS, J E MÜller, T SCHOLTEN, AND W P FRITSCH \\ From the Department of Medicine A, University of Düsseldorf, Düsseldorf, West-Germany
}

SUMMARY Provided the intragastric $\mathrm{pH}$ is greater than 6 and the collected gastric juice is boiled and neutralised immediately, considerable amounts of gastrin-like immunoreactivity can be found in human gastric juice. Characterisation according to size and charge reveals that nearly all the gastrin-like immunoreactivity is similar to gastrin 1-17. Direct stimulation of the G-cells with protein solution is followed by a significant and simultaneous increase of acid secretion, serum gastrin, and gastrin output into the lumen of the stomach in control subjects and patients with duodenal ulcer.

The occurrence of gastrin in gastric juice has been a matter of dispute. Sircus ${ }^{1}$ suggested the presence of a secretagogue in the gastric juice of ZollingerEllison patients. Jordan and $\mathrm{Yip}^{2}$ reported that gastrin-like immunoreactivity was detectable in gastric juice of patients without gastrointestinal disease in the fasting state and after stimulation of secretion. Intraluminal gastrin has been thought to be related to peptic ulcer disease. ${ }^{3}$ Other authors have questioned the assay conditions used in the measurement of gastrin-like activity in gastric juice, ${ }^{45}$ pointing out possible artefacts in the gastrin radioimmunoassay. ${ }^{6}$

The present study was performed to determine whether gastrin protected from acid proteolysis and enzymatic degradation is really present in gastric juice or its apparent presence there is an artefact in the radioimmunoassay system.

\section{Methods}

COLLECTION OF GASTRIC JUICE AND BLOOD SAM P LES

Fifteen healthy volunteers and 14 duodenal ulcer patients were studied. Informed written consent was obtained from each subject. After an overnight fasting period of 12 hours, gastric tubes were positioned in the gastric fundus and antrum under fluoroscopic control. A polyethylene cannula was placed in the antecubital vein. After a rest period of 30 minutes, residual gastric contents were removed and submitted to gastrin assay. Basal acid output was

Received for publication 1 April 1980 determined over 30 minutes, and two basal samples of venous blood for gastrin assay were obtained. Then gastric perfusion was performed for two periods with $50 \mathrm{ml} 0 \cdot 15 \mathrm{M}$ sodium phosphate buffer pH 7.0 $(299 \mathrm{mosm} / \mathrm{kg})$ per 15 minutes and for 10 consecutive 15 minute periods with $50 \mathrm{ml} 10 \%$ peptone pH 7.0 (540 mosm $/ \mathrm{kg}$, Difco Laboratories, Detroit, Michigan, USA). The perfusate entered the stomach via the tube positioned in the gastric fundus and was collected via the antral catheter in a glass cylinder standing in a boiling water bath. The gastric juice was immediately neutralised by addition of $0 \cdot 1$ $\mathrm{N}$ sodium hydroxide. Before neutralisation, the $\mathrm{pH}$ of the gastric juice was recorded. Acid secretion per 15 minute sample was determined. Aliquots of venous blood were taken at the end of each collection period. Serum and gastric juice samples were frozen after collection and treatment and stored at $-20^{\circ} \mathrm{C}$.

In five healthy volunteers and five patients with duodenal ulcer the stomach was perfused in the same way with $0.42 \mathrm{M}$ sodium bicarbonate adjusted to $\mathrm{pH} 5.5$ with $1 \mathrm{~N}$ hydrochloric acid $(825 \mathrm{mosm} / \mathrm{kg}$ ) and $20 \%$ peptone $\mathrm{pH} 5.5(1080 \mathrm{mosm} / \mathrm{kg})$. The recovered perfusates were treated as described above.

To exclude G-cell damage caused by phosphate buffer, the stomach of four control persons and four duodenal ulcer patients was alternately perfused for six consecutive 15 minute periods with $0.6 \mathrm{M}$ sodium bicarbonate adjusted to $\mathrm{pH} 7.0$ with $1 \mathrm{~N}$ hydrochloric acid and with $0.15 \mathrm{M}$ sodium phosphate buffer $\mathrm{pH} 7.0$ (flow rate $50 \mathrm{ml} / 15 \mathrm{~min}$ ). The perfusates were boiled, neutralised, frozen, and stored at $-20^{\circ} \mathrm{C}$. 
RADIOIMMUNOASSAY OF GASTRIN

To exclude artefacts in the radioimmunoassay systems caused by interaction of unknown factors in the gastric juice with the antigen-antibody binding reaction, serum and gastric juice were assayed for gastrin with two RIA systems (system A and B) using different antisera (system A: 662, system B: TB). Synthetic human gastrin 1-17 (SHG), (ICI Limited, Macclesfield, England), was used as standard and purified ${ }^{125}$ I-labelled SHG as tracer in both assay systems. For separation of antibodybound and free-labelled antigen Amberlite CG4 I (Behringwerke AG, Marburg, Germany) was used in system $\mathrm{A}$, whereas a $10 \mathrm{~g} \%$ charcoal suspension (Norit A, Sigma Chemical Company, St Louis, USA) was used in system B. In system A (B) the standard diluent consisted of $0.02 \mathrm{M}$ barbital buffer ( $\mathrm{pH} 8.4)$ with $0.2 \%(0.1 \%)$ bovine serum albumin (BSA). In both RIA systems $100 \mu \mathrm{l}$ of serum and gastric juice were assayed for gastrin in a final incubation volume of $2.5 \mathrm{ml}$ using the antisera at a dilution of 1:100000 (662) and 1:40000 (TB) with a sensitivity of $0.8 \mathrm{pg} / \mathrm{ml}(662)$ and $0.2 \mathrm{pg} / \mathrm{ml}$ (TB). The antiserum TB measured gastrin 1-17 and gastrin 1-34 with equimolar potency. In the RIA system using antiserum 662 gastrin 1-34 reacted with a potency about $80 \%$ that of gastrin $1-17$ on a molar basis. The antisera 662 and TB showed little crossreaction with fragments of the gastrin molecule. The ratio between $\mathrm{ID}_{50}$ - that is, the molar concentration of antigen able to inhibit the antibody binding of the labelled antigen to $50 \%$ of the initial valueand $\mathrm{ID}_{50}$ for different antigens was: gastrin 11-17 0.173 (662) and 0.016 (TB), gastrin 14-17 0.049 (662) and 0.002 (TB). Gastric juice from which gastrin had been removed did not crossreact with either antiserum.

\section{RECOVERY STUDIES}

One hundred picograms SHG were incubated with $1 \mathrm{ml}$ of untreated gastric juice for 10 minutes at different $\mathrm{pH}$ values. After incubation, samples were immediately neutralised and boiled. Gastrin concentration was measured, and recovery was determined.

\section{GEL FILTRATION}

Two millilitre samples of gastric juice were applied to $16 \mathrm{~mm} \times 1000 \mathrm{~mm}$ Sephadex G50 superfine columns with a constant flow-rate of $4.2 \mathrm{ml} / \mathrm{h}$ at $4^{\circ} \mathrm{C}$ and eluted with $0.02 \mathrm{M}$ barbital buffer ( $\mathrm{pH} 8.4$ ) containing $2 \mathrm{mg}$ BSA per $\mathrm{ml}$. The columns were calibrated with ${ }^{131} \mathrm{I}$-albumin, ${ }^{131} \mathrm{I},{ }^{125} \mathrm{I}-\mathrm{SHG}$, and serum from a patient with the Zollinger-Ellison syndrome. Fractions of $1.3 \mathrm{ml}$ were counted for radioactivity and assayed for gastrin.
STARCH GEL ELECTROPHORESIS

Eighty microlitre samples of boiled and neutralised gastric juice were run on starch gel electrophoresis according to the method of Smithies, ${ }^{7}$ together with SHG added to $80 \mu$ l of boiled and neutralised gastric juice from which endogenous gastrin had been removed (by repeated treatment with Amberlite anion exchange resin) and with serum from Zollinger-Ellison patients. After electrophoresis, gel segments were cut from the slab and frozen for at least four hours. After thawing, gastrin was eluted by maceration in $0.02 \mathrm{M}$ barbital buffer ( $\mathrm{pH} \mathrm{8.4)}$ containing $0 \cdot 2 \%$ BSA. Gel particles were removed by centrifugation and the supernatant solutions were assayed for gastrin. Bromphenol blue was added to the serum before electrophoresis to stain serum albumin.

\section{COMPETITIVE INHIBITION CURVES}

Inhibition of binding of ${ }^{125} \mathrm{I}-\mathrm{SHG}$ to anti-SHG antibodies by gastric juice gastrin-like immunoreactivity was compared with the inhibition produced by unlabelled SHG.

\section{STATISTICAL EVALUATION}

The statistical significance of the difference of the mean values was evaluated by Wilcoxon's test ${ }^{8}$ for paired comparison, $P$ values less than 0.05 being considered significant.

\section{Results}

\section{CONDITIONS FOR DETECTION OF GASTRIN} IN GASTRIC JUICE

No gastrin could be detected in untreated gastric juice. In some of the perfusates carried out with

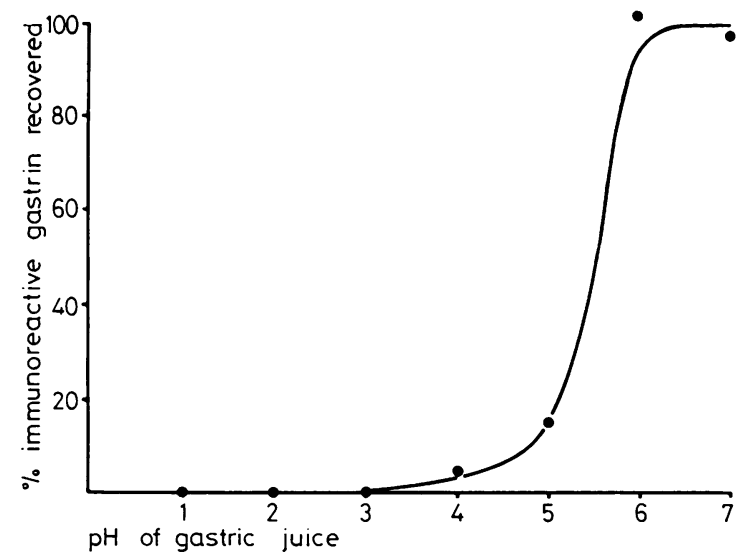

Fig. 1 Recovery of 100 pg synthetic human gastrin 1-17, expressed in per cent, after a 10 minute incubation with $1 \mathrm{ml}$ untreated gastric juice at different $\mathrm{pH}$ values. 


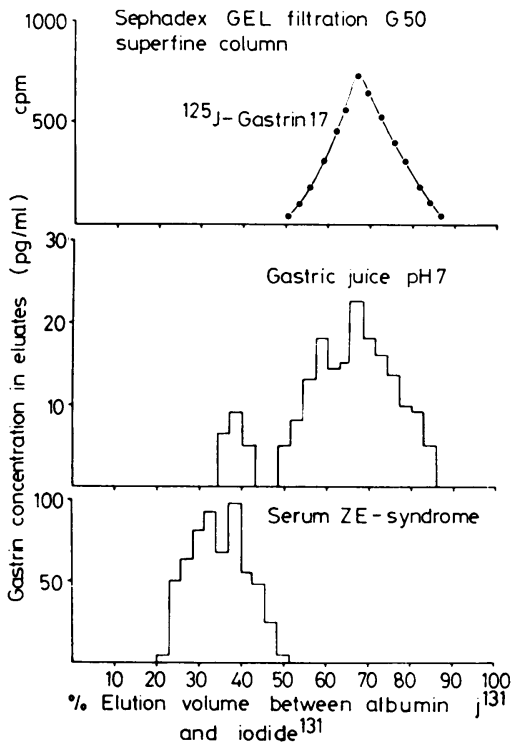

Fig. 2 Sephadex G50 superfine elution profile of ${ }^{125}$ I-gastrin 1-17 and immunoreactive gastrin components in neutralised gastric juice and in serum of a patient with the Zollinger-Ellison syndrome.

sodium bicarbonate $\mathrm{pH} 5.5$ and $20 \%$ peptone solution $\mathrm{pH} 5.5$ trace amounts of gastrin-like immunoreactivity were found. The lowest $\mathrm{pH}$ of the recovered perfusates varied between 3.1 (bicarbonate) and 4.0 (peptone). Immunoreactive gastrin was detected in all samples of gastric juice recovered during perfusion of the stomach with sodium phosphate $\mathrm{pH} 7$ and $10 \%$ peptone $\mathrm{pH} 7$. Minimum $\mathrm{pH}$ of the recovered perfusates was greater than 6 in all experiments. As regards the release of gastrin into gastric juice per collection period, the perfusions of the stomach with sodium bicarbonate $\mathrm{pH} 7.0$ and with sodium phosphate buffer $\mathrm{pH} 7.0$ produced identical results. Samples of neutralised and boiled gastric juice diluted $1: 25$ in the incubation medium for gastrin assay did not cause a significant reduction in $\mathrm{pH}$. Taking the somewhat different specificity of the two antisera into account, the RIA systems used in this study yielded consistent results.

GASTRIN RECOVERY FROM GASTRIC JUICE SHG-recovery after a 10 minute incubation with unboiled gastric juice was $\mathrm{pH}$-dependent, showing a steep increase between pH 5 and 6 (Fig. 1).

MOLECULAR FORMS OF GASTRIN IN

GASTRIC JUICE

When subjected to gel filtration on Sephadex G50 superfine columns nearly all the immunoreactivity in gastric juice eluted similarly to labelled gastrin 1-17 (Fig. 2). A small amount corresponded to gastrin 1-34. Starch gel electrophoresis also showed that the predominant amount of immunoreactive material was similar to gastrin 1-17 (Fig. 3); small amounts migrated like gastrin 1-34. The competitive inhibition curve of gastrin-like immunoreactivity in gastric juice was superimposable on that of SHG (Fig. 4).

CONTENT OF GASTRIC JUICE GASTRIN AT REST AND DURING SECRETORY STIMULATION Perfusion of the stomach with sodium phosphate pH 7 led to an insignificant increase of acid secretion in the control group (Fig. 5) and did not change serum gastrin levels. Gastrin was detected in the

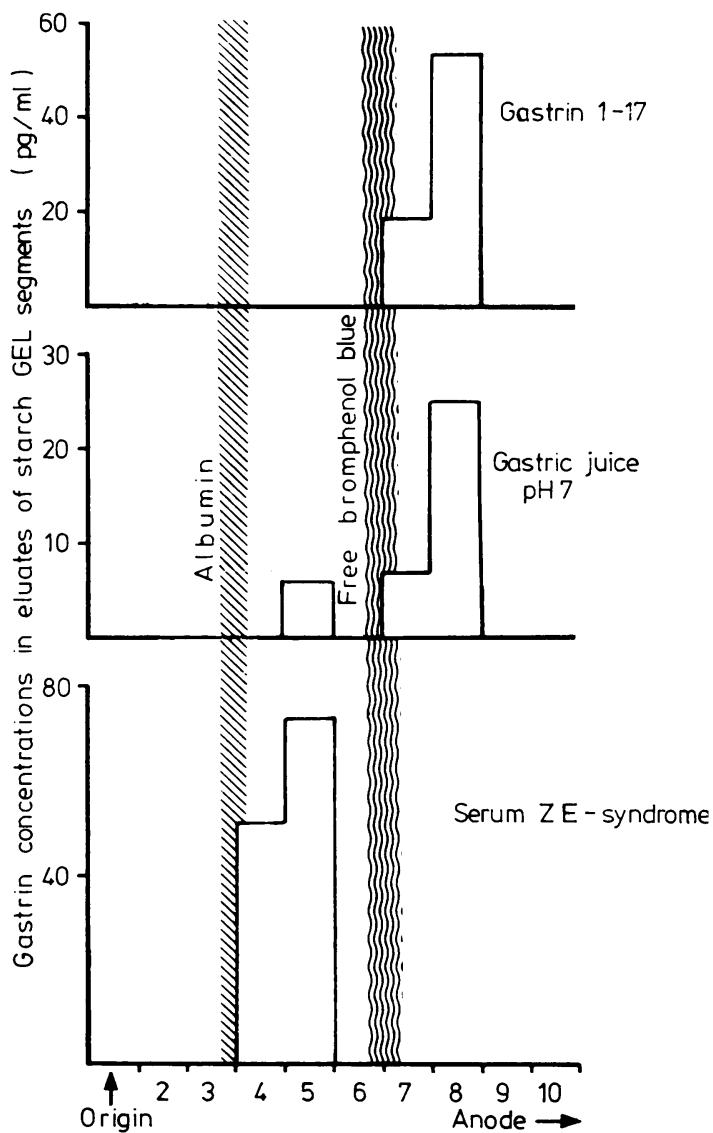

Fig. 3 Distribution of immunoreactive gastrin components on starch gel electrophoresis in boiled and neutralised gastrin free gastric juice to which had been added synthetic human gastrin 1-17 (top), in neutralised and boiled gastric juice (middle), and in serum of a patient with the Zollinger-Ellison syndrome (bottom). 


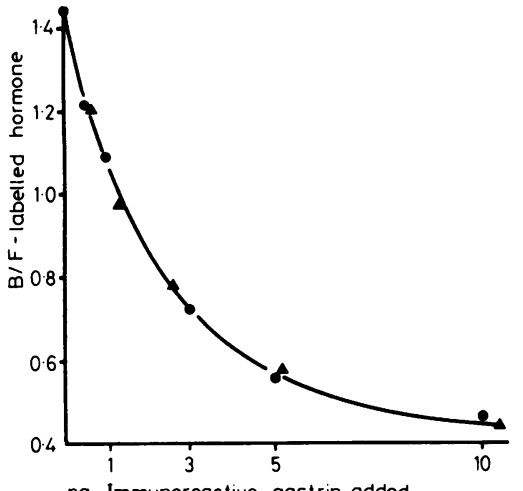

pg Immunoreactive gastrin added

Fig. 4 Ratio (B/F) of antibody-bound (B) to free $(F)$ ${ }^{125}$ I-labelled synthetic human gastrin 1-17 as a function of concentration of unlabelled synthetic human gastrin 1-17 (O ) The gastrin concentration in gastric juice ( $\Delta$ ) was determined by reference to the standard curve of synthetic human gastrin 1-17. The concentration of each dilution was then calculated from the dilution factors employed. Antiserum: TB, final dilution 1:40 000 .

gastric perfusate. Stimulation with $10 \%$ peptone solution pH 7 induced a significant $(\mathbf{P}<0.001)$ and simultaneous increase of acid secretion, serum gastrin levels, and the amounts of gastrin released into the lumen of the stomach. There occurred a plateau in respect of all parameters for the entire period of perfusion. Duodenal ulcer patients showed results similar to the control group (Fig. 6).

The amounts of gastrin released into gastric juice ranged from 1 to $55 \mathrm{ng}$ SHG equivalent per $15 \mathrm{~min}$ sample; usually the concentration did not exceed $300 \mathrm{pg} / \mathrm{ml}$ (range $20-700 \mathrm{pg} / \mathrm{ml}$ ). There was a considerable variation between individuals for gastrin output into the gastric juice in comparable collection periods. During perfusion with sodium phosphate and after the stimulation plateau had been reached, the output of gastrin into gastric juice was rather constant for a given subject.

\section{Discussion}

Dissociation of antigen-antibody complexes at low $\mathrm{pH}$ and proteolytic damage of labelled antigen and antibody are the source of erroneously high concentrations in the radioimmunoassay of peptide hormones in gastric or duodenal secretions. ${ }^{6}{ }^{9}$ On the other hand, falsely low or zero values can be due to acid hydrolysis and enzymatic degradation of gastrin before assay. In our experiments incubation damage was avoided by neutralising and boiling the collected samples of gastric juice immediately. As the dilution of gastric juice was $1: 25$, the $\mathrm{pH}$ of the incubation volume remained unchanged. The investigations of Stadil et al..$^{5}$ demonstrated a great loss of gastrin 1-17 immunoreactivity after as little as 30 seconds'
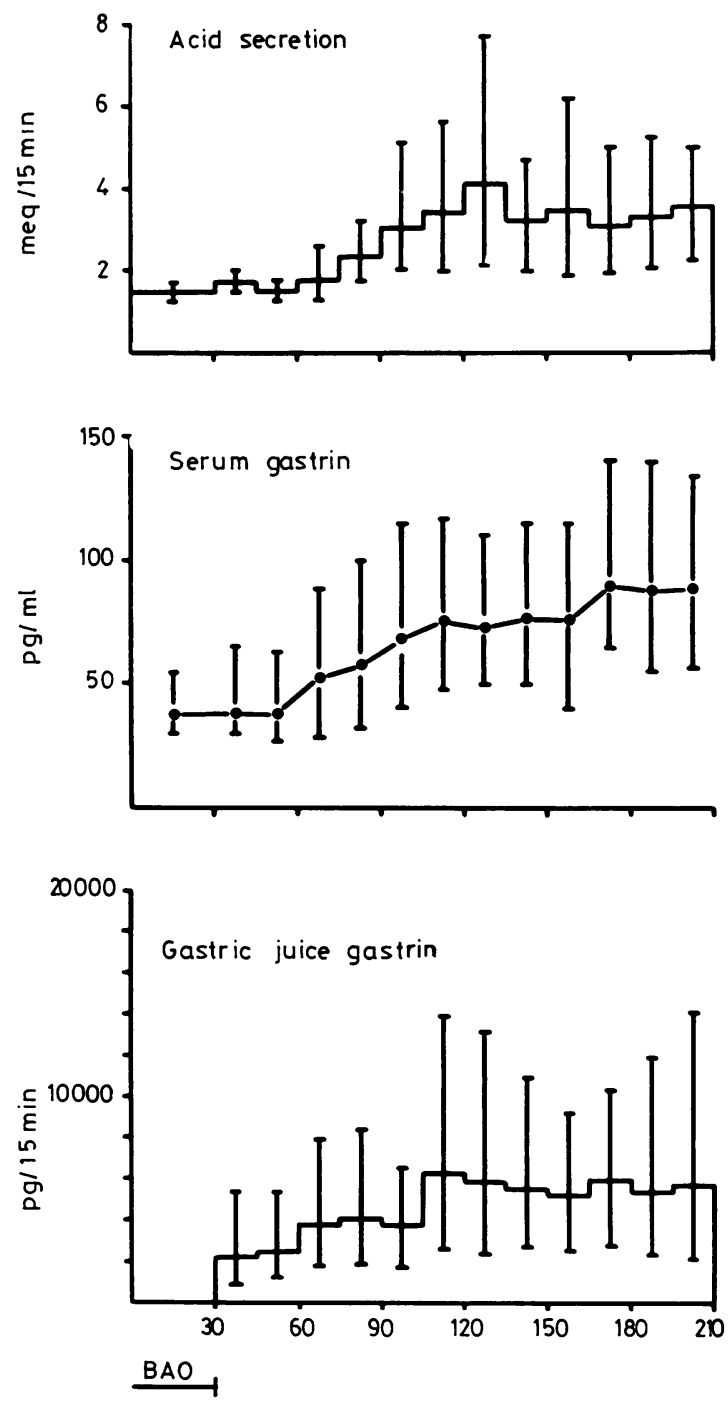

$0.15 \mathrm{~m}$ Sodium phosphate $\mathrm{pH} 750 \mathrm{ml} / 15 \mathrm{~min}$

$10 \%$ Peptone $\mathrm{pH} 750 \mathrm{ml} / 15 \mathrm{~min}$

Fig. 5 Time-course of acid secretion, serum gastrin, and gastric juice gastrin output in healthy volunteers $(n=15)$ under basal conditions $(B A O)$ and during perfusion of the stomach with $0.15 \mathrm{M}$ sodium phosphate buffer (pH 7) and 10\% peptone solution (pH 7). Flow rate $50 \mathrm{ml} / 15 \mathrm{~min}$. Bars represent mean $\pm S E$. For acid secretion, serum gastrin and gastric juice gastrin the differences at all time intervals after 75 minutes were statistically significant by Wilcoxon's test $(\mathrm{P}<0.001)$. 

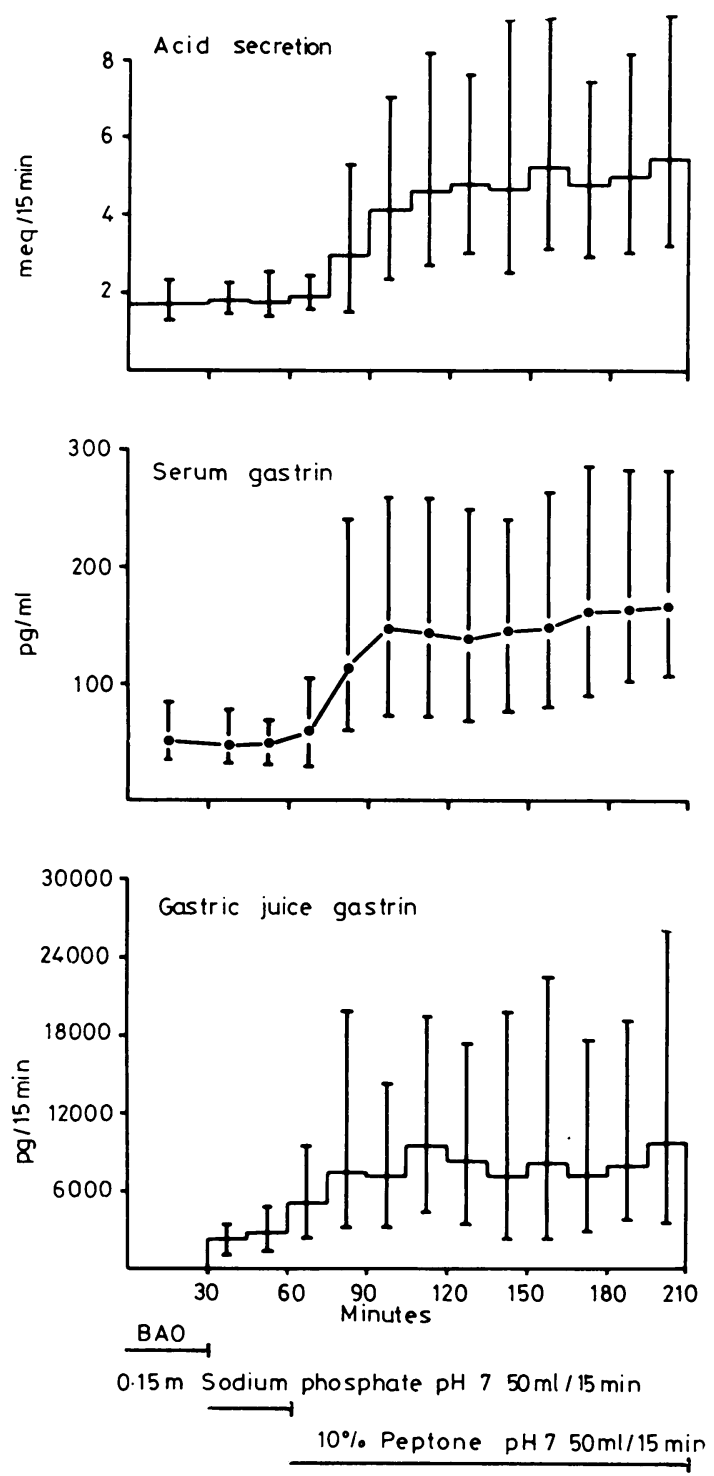

Fig. 6 Same as Fig. 5 for duodenal ulcer patients $(n=14)$. After 75 minutes, differences for acid secretion, serum gastrin, and gastric juice gastrin were statistically significant by Wilcoxon's test $(\mathrm{P}<0.001)$.

exposure to untreated gastric juice. Our results support the conclusion that this is due to $\mathrm{pH}$ dependent peptic cleavage of gastrin. We found that recovery of gastrin 1-17 from untreated gastric juice is inversely proportional to the $\mathrm{pH}$-dependency of peptic activity as reported by Piper and Fenton, ${ }^{10}$ and we were unable to find any gastrin-like immunoreactivity in untreated gastric juice. Perfusion of the stomach with sodium bicarbonate and peptone solution at $\mathrm{pH} 5.5$ resulted in an increase of intragastric $\mathrm{pH}$ which was apparently inadequate to abolish peptic activity entirely, so that trace amounts of gastrin-like immunoreactivity were detected in only a few samples of gastric juice. However, gastric perfusion with sodium phosphate and peptone $\mathrm{pH} 7$ produced adequate alkalinity in the gastric contents to protect gastrin from degradation, and all samples collected this way contained considerable amounts of gastrin-like immunoreactivity. It seems possible that the failure of Stadil et al..$^{5}$ and Straus and Yalow $^{6}$ to detect gastrin in gastric juice might have been caused by complete intragastric degradation of the gastric juice gastrin by pepsin and other proteolytic enzymes.

There was no difference between synthetic human gastrin 1-17 and gastric juice immunoreactivity as regards size, charge, and immunoreactivity with the antibodies used. Small amounts of immunoreactivity similar to endogenous human gastrin 1-34 were also detected.

Our data showed that a protein solution is suitable for the stimulation of gastrin output into gastric juice. The simultaneous increase of gastrin output into blood and gastric juice on stimulation of secretion, suggests that gastrin is bidirectionally released from the antral G-cells into the circulation and the lumen of the stomach. The absence of gastrin 1-17 in the gastric juice of antrectomised patients (Hengels, unpublished data) supports this assumption. Anderson ${ }^{11}$ reported the proof of gastrin in buffer perfusates from the isolated gastric antrum of dogs. This was confirmed by Uvnäs-Wallensten ${ }^{12}$ in cats. Our results are in agreement with the experiments of these investigators. The biological significance of gastric juice gastrin in man and its route of secretion are under investigation.

The authors thank Mrs Gerda Berti for excellent technical assistance.

\section{References}

${ }^{1}$ Sircus W. Evidence for a gastric secretagogue in the circulation and gastric juice of patients with the Zollinger-Ellison syndrome. Lancet 1964; 2: 671-2.

${ }^{2}$ Jordan PH Jr, Yip BSSC. The presence of gastrin in fasting and stimulated gastric juice of man. Surgery 1972; 72: 352-6.

${ }^{3}$ Fiddian-Green RG. Is peptic ulceration a hormonal disease? Lancet 1977; 1: 74-7.

${ }^{4}$ Malmström J, Stadil F, Rehfeld JF. Questioning gastrin assay methods. (Letter) Surgery 1973; 73: 481-2.

${ }^{5}$ Stadil F, Malmström J, Miyata M, Rehfeld JF. Effect of histamine on immunoreactive gastrin in gastric juice and in serum. Surgery 1975; 77: 345-50. 
${ }^{6}$ Straus E, Yalow RS. Artifacts in the radioimmunoassay of peptide hormones in gastric and duodenal secretions. $J$ Lab Clin Med 1976; 87: 292-8.

${ }^{7}$ Smithies O. Zone electrophoresis in starch gels and its application to studies of serum proteins. Adv Protein Chem 1959; 114: 65-113.

${ }^{8}$ Wilcoxon F. Probability tables for individual comparisons by ranking methods. Biometrics 1947; 3: 119-22.

${ }^{9}$ Straus E. Radioimmunoassay of gastrointestinal hormones. Gastroenterology 1978; 74: 141-52.

${ }^{10}$ Piper DW, Fenton BH. pH stability and activity curves of pepsin with special reference to their clinical importance. Gut 1965; 6: 506-8.

${ }^{11}$ Andersson S, Nilsson G. Appearance of gastrin in perfusates from the isolated gastric antrum of dogs. Scand J Gastroenterol 1974; 9: 619-21.

${ }^{12}$ Uvnäs-Wallensten $\mathrm{K}$. Occurrence of gastrin in gastric juice, in antral secretion, and in antral perfusates of cats. Gastroenterology 1977; 73: 487-91. 